\title{
Spectroscopic characterization of high $k$ dielectrics: Applications to interface electronic structure and stability against chemical phase separation
}

\author{
C. Krug and G. Lucovsky ${ }^{a}$ \\ Department of Physics, North Carolina State University, Campus Box 8202, Raleigh, North Carolina 27695
}

(Received 22 December 2003; accepted 29 March 2004; published 19 July 2004)

\begin{abstract}
Extensive spectroscopic characterization of high $k$ materials under consideration for replacing $\mathrm{Si}$ oxide as the gate dielectric in Si-based microelectronic devices has been accomplished. Band offset energies of $\mathrm{Zr}$ silicates with respect to $\mathrm{Si}$ have been determined as a function of silicate alloy composition by combining near-edge $\mathrm{x}$-ray absorption fine structure spectroscopy, vacuum-ultraviolet spectroscopic ellipsometry, x-ray photoelectron spectroscopy (XPS), Auger electron spectroscopy, and $a b$ initio calculations on cluster models. These studies provide insight that applies to both transition metal- and rare earth-based dielectrics, including binary oxides and silicate and aluminate alloys. Results have been used to estimate the electronic conduction through Hf silicate films as a function of alloy composition. Thermally induced chemical phase separation in $\mathrm{Zr}$ silicate films has been characterized using XPS, Fourier transform infrared spectroscopy, x-ray diffraction, high-resolution transmission electron microscopy, and extended x-ray absorption fine structure spectroscopy. Our results indicate separation into a noncrystalline, Si-rich phase and either nano- or microcrystalline $\mathrm{ZrO}_{2}$, depending on the original film stoichiometry. (c) 2004 American Vacuum Society. [DOI: 10.1116/1.1755714]
\end{abstract}

\section{INTRODUCTION}

The search for a material of high dielectric constant (high $k$ ) to replace nitrided silicon oxide as the gate dielectric in advanced microelectronic devices has been concentrated on $\mathrm{Hf}$ and $\mathrm{Zr}$-based materials. The pure transition metal oxides are naturally attractive due to their high $k$ values, but silicate alloys have shown enhanced thermal stability against crystallization. Additional issues that have been addressed regarding thin high $k$ films on $\mathrm{Si}$ include: band alignment, interfacial electronic states, fixed charge, charge trapping, electron mobility at the interface with $\mathrm{Si}$, and reliability with respect to dielectric breakdown. The vast knowledge base available regarding the $\mathrm{SiO}_{2} / \mathrm{Si}$ interface has been of limited use, and new understandings need to be developed.

In this article we use spectroscopic data to address (i) the band alignment of transition metal silicates with $\mathrm{Si}$ and (ii) chemical phase separation during thermal annealing of $\mathrm{Zr}$ silicate alloys. In the first case, we build models that ultimately identify the optimal silicate alloy composition regarding suppression of direct electron tunneling. In the second, we present a wealth of experimental data that support a recent analysis of the thermodynamics of the $\mathrm{Si}-\mathrm{O}-\mathrm{Zr}$ system. Our experimental data are the result of extensive spectroscopic characterization of $\mathrm{Hf}$ and $\mathrm{Zr}$ silicate alloys using x-ray absorption spectroscopy (XAS), including extended $\mathrm{x}$-ray absorption fine structure (EXAFS) and near-edge $\mathrm{x}$-ray absorption fine structure (NEXAFS) spectroscopies, vacuum-ultraviolet spectroscopic ellipsometry (VUV SE), $\mathrm{x}$-ray photoelectron spectroscopy (XPS), Auger electron spectroscopy (AES), Fourier transform infrared spectroscopy

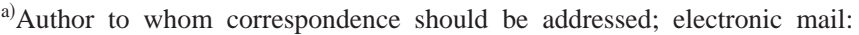
lucovsky@unity.ncsu.edu
}

(FTIR), x-ray diffraction (XRD), and high-resolution transmission electron microscopy (HRTEM).

\section{EXPERIMENTAL PROCEDURES}

XPS, AES, XAS, VUV SE, and HRTEM measurements were performed on $\mathrm{Hf}$ and $\mathrm{Zr}$ silicate films ranging in thickness from 20 to $50 \mathrm{~nm}$ on $\mathrm{Si}(100)$; films thicker than $150 \mathrm{~nm}$ were deposited: (i) on $\mathrm{Si}(100)$ for FTIR and XRD and (ii) on fused silica for XAS measurements. The remote plasma enhanced chemical vapor deposition (RPECVD) process used for sample preparation is described in detail elsewhere. ${ }^{1,2}$ In summary, radio frequency excitation $(13.56 \mathrm{MHz}, 15 \mathrm{~W})$ of a $\mathrm{He} / \mathrm{O}_{2}(20: 1)$ mixture produces a plasma. Excited species reach the sample holder in the plasma afterglow region as a result of gas flow. $\mathrm{Si}$ and $\mathrm{Zr}(\mathrm{Hf})$ source gases $\left[2 \% \mathrm{SiH}_{4}\right.$ in $\mathrm{He}$ and $\mathrm{Zr}(\mathrm{IV}) t$-butoxide (Hf(IV) $t$-butoxide) carried by $\mathrm{He}$ ] are delivered directly onto the substrate by two different shower-head injectors. The substrate is kept at $300^{\circ} \mathrm{C}$, and the total pressure during deposition is 0.3 Torr.

Changing the flow rates of the transition metal and $\mathrm{Si}$ source gases varied the composition of the deposited films. Substrates were treated in a $\mathrm{H}_{2} \mathrm{O} / \mathrm{HF}(100: 1)$ solution prior to film deposition to remove the superficial native oxide. Also, $\sim 3 \mathrm{~nm}$ of $a-\mathrm{SiO}_{2}$ were deposited on the $\mathrm{Si}$ substrates by RPECVD before silicate deposition. This had two purposes: (i) to suppress reactions of the $\mathrm{Zr}(\mathrm{Hf})$ source gas with the Si substrate and (ii) to prevent reactions between the alloy and the Si substrate during postdeposition annealing. Thermal annealing was performed ex situ in an inert Ar ambient for $1 \mathrm{~min}$.

The composition of silicate alloys, reported as $x$ in $\left(\mathrm{MO}_{2}\right)_{x}\left(\mathrm{SiO}_{2}\right)_{1-x}(\mathrm{M}=\mathrm{Zr}, \mathrm{Hf})$, was obtained from on-line 
AES measurements using the ratio of the derivative spectrum peak-to-peak heights of $\mathrm{Zr}_{M N N(M V V)}$ and $\mathrm{O}_{K L L(K V V)}$ features. The Auger process was initiated by a $3 \mathrm{keV}$ electron beam, which was defocused to prevent damage to the samples. These measurements were once calibrated against Rutherford backscattering spectrometry, which indicated that the alloy films are homogeneous and fully oxidized; the uncertainty in composition is $\delta x= \pm 0.03$. FTIR absorption measurements, in the mid-IR (4000-400 $\left.\mathrm{cm}^{-1}\right)$ and far-IR $\left(700-50 \mathrm{~cm}^{-1}\right)$, were performed in the transmission mode. XPS measurements of $\mathrm{O} 1 s, \mathrm{C} 1 s, \mathrm{Zr} 3 d$, and $\mathrm{Si} 2 p$ core levels were made using nonmonochromatized $\operatorname{Mg} K \alpha$ radiation (1253.6 $\mathrm{eV}$ ) and a pass energy of $20 \mathrm{eV}$. Data were corrected for charging effects using the $\mathrm{C} 1 s$ peak at $284.6 \mathrm{eV}$ from adventitious carbon contamination on the sample surface. EXAFS and NEXAFS measurements were made at the National Synchrotron Light Source at Brookhaven National Laboratory. Absorption spectra for the $\mathrm{O} K_{1}$ edge NEXAFS were recorded by detecting the primary photoelectron yield, and absorption data for EXAFS and NEXAFS at the $\mathrm{Zr} K_{1}$ edge were obtained by monitoring $\mathrm{x}$-ray fluorescence. Ab initio calculations have been discussed in detail elsewhere. ${ }^{3}$

\section{BAND ALIGNMENT WITH RESPECT TO Si}

In the following we show the application of various spectroscopic techniques to the determination of band alignment at the transition metal silicate/Si interface as a function of silicate composition. ${ }^{2,4,5}$ Our results qualitatively apply to transition metal aluminate alloys as well. Starting from the electronic structure of $\mathrm{ZrO}_{2}$, we use spectroscopic data to analyze the silicate conduction and valence band edges, thus building the complete band diagram. We then consider atomic $d$-state energy as a scaling variable for the electronic properties of transition metal- and rare earth-based dielectrics. Finally, we develop a model to estimate electron tunneling through silicate alloys as a function of silicate composition.

Figure 1 is a schematic representation of the intra- and interatomic electronic transitions for $\mathrm{ZrO}_{2}$ that are addressed in this article. The intra-atomic transitions are dipole allowed and reflect the atomic states of $\mathrm{Zr}$, while the interatomic transitions terminate in mixed $\mathrm{Zr}$ and $\mathrm{O}$ states, and therefore are qualitatively different than the intra-atomic transitions. The relative ordering of the conduction band states is supported by molecular orbital calculations of small clusters incorporating group IVB $\mathrm{Ti}, \mathrm{Zr}$ and $\mathrm{Hf}$ atoms in octahedral and tetrahedral bonding arrangements with oxygen neighbors. ${ }^{6-8}$ The top of the valence band is associated with nonbonding oxygen $2 p \pi$ states, and the first two conduction bands are associated with transition metal $d$ states. The energy separation between the top of the valence band in $\mathrm{ZrO}_{2}$ and the threshold absorption to the $\mathrm{O} 2 p^{*}$ states mixed with $\mathrm{Zr} 5 s^{*}$ states defines an ionic band gap of essentially the same width as in nontransition metal insulating oxides such as $\mathrm{MgO}$ or $\mathrm{Al}_{2} \mathrm{O}_{3}, \sim 8-9 \mathrm{eV}$, $^{7,9}$

The lowest conduction band states of $\mathrm{ZrO}_{2}$ as determined from XAS and VUV SE measurements are associated with
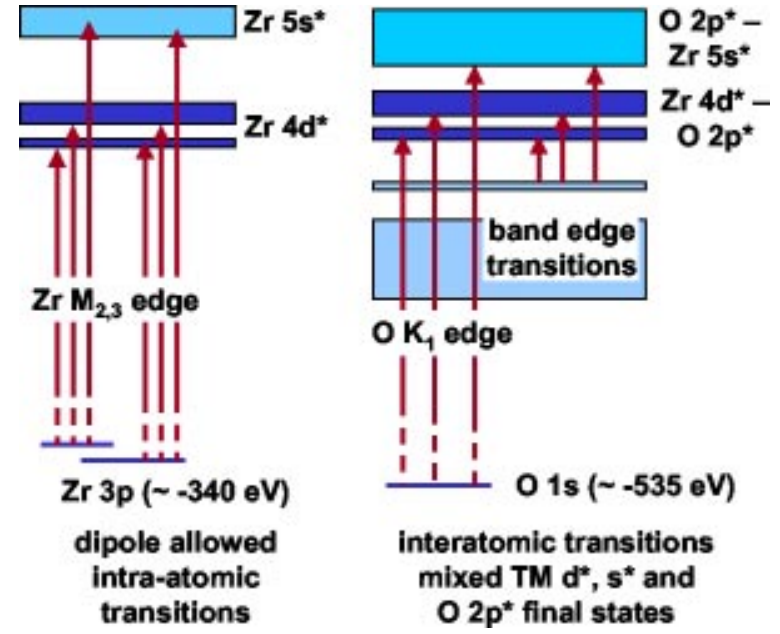

FIG. 1. (Color online) Schematic representation of the intra-atomic $\operatorname{Zr} M_{2,3}$, and interatomic $\mathrm{O} K_{1}$ and band edge transitions for $\mathrm{ZrO}_{2}$. The ordering of the energy states is derived from $a b$ initio molecular orbital calculations on small neutral clusters.

$\mathrm{Zr} 4 d^{*}$ states. Figure 2(a) displays the deconvolved $\mathrm{Zr} M_{3}$ NEXAFS spectrum of crystalline $\mathrm{ZrO}_{2}$, which displays features associated with transitions from $\mathrm{Zr} 3 p_{3 / 2}$ states to $\mathrm{Zr} 4 d^{*}$ (split) and $\mathrm{Zr} 5 s^{*}$ states. The symmetry-determined splitting of the $4 d^{*}$ states in Table I is designated as $\Delta\left(d^{*}\right)$, and the energy separation between the lowest $4 d^{*}$ state, and the center of the $5 s^{*}$ band is designated as $\Delta\left(d^{*}, s^{*}\right)$. The table includes experimental results for $\mathrm{ZrO}_{2} M_{2,3}$ and $\mathrm{HfO}_{2} N_{3}$ spectra. The splitting of the $5 d^{*}$ states in the $\mathrm{Hf} N_{3}$ spectrum is not spectroscopically resolved due to an increase in linewidth that scales with atomic number. Table II includes the spectroscopically determined spin-orbit splittings of Ti, Zr, and Hf $p_{1 / 2}$ and $p_{3 / 2}$ states. Figure 2(b) displays the $\mathrm{O} K_{1}$ NEXAFS spectrum of crystalline $\mathrm{ZrO}_{2}$. The two bands at the low photon energy edge are associated with transitions to mixed $\mathrm{O} 2 p^{*}-\mathrm{Zr} 4 d^{*}$ states. A third multi-component band has considerable $\mathrm{O} 2 p^{*}$ character, mixed with $\mathrm{Zr} 5 s^{*}$, and additional features at higher energies due to mixing with $\mathrm{Zr} 5 p^{*}$ states. Table I includes the $\Delta\left(d^{*}\right)$ splitting, as well as the energy separation between the lower energy $d^{*}$ state and the first spectral peak of the $5 s^{*}$ band, $\Delta\left(d^{*}, s^{*}\right)$. Figure 2(c) displays the band edge optical absorption constant $\alpha$ of $\mathrm{ZrO}_{2}$ obtained from analysis of VUV SE data. The lowest lying transitions in the crystalline $\mathrm{ZrO}_{2} \mathrm{O} K_{1}$ edge and band gap transitions are associated with $\mathrm{Zr} 4 d^{*}$ states.

The assignments in Fig. 2 are based in part on comparisons with the results of our $a b$ initio calculations. The $a b$ initio method used is based on a self-consistent field Hartree-Fock calculation, followed by a configuration interaction (CI) refinement utilizing the variational theorem. Proceeding in this way, the calculations include final state effects, in particular the Coulomb attractions between core and valence band holes, and the excited electrons. Table I summarizes the energy splittings, $\Delta\left(d^{*}\right)$ and $\Delta\left(d^{*}, s^{*}\right)$, of the band edge electronic states for $\mathrm{ZrO}_{2}$ and $\mathrm{HfO}_{2}$ as determined 

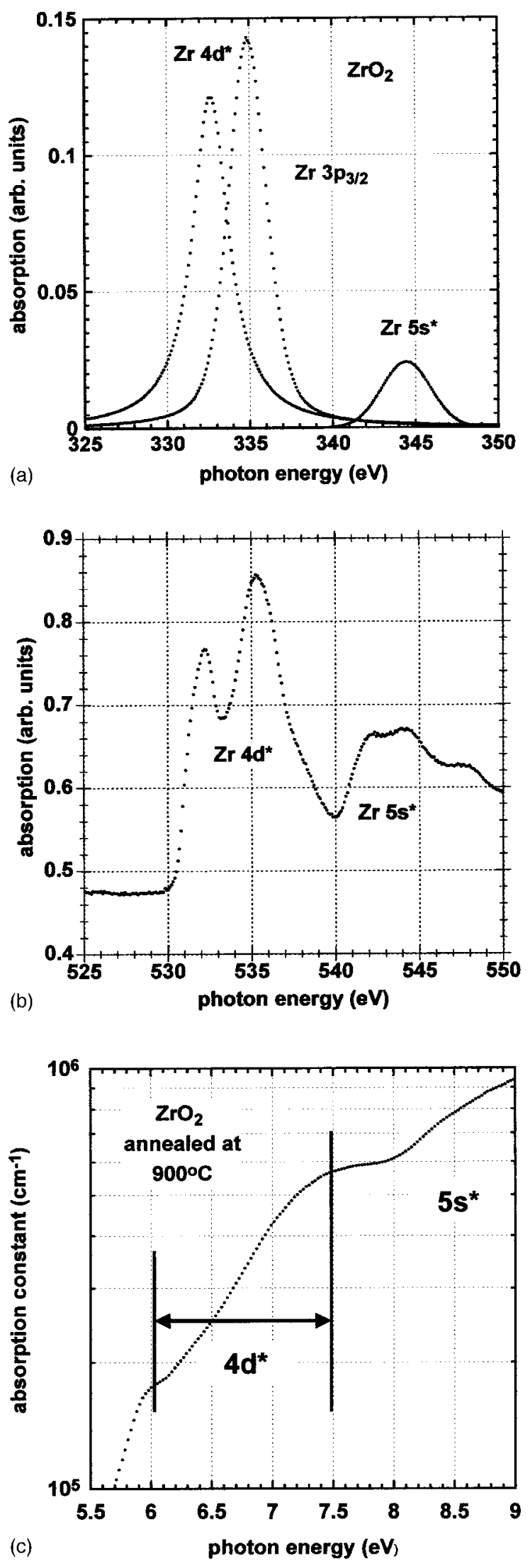

FIG. 2. $\mathrm{ZrO}_{2}$ spectra: (a) $\mathrm{Zr} M_{3}$ and (b) $\mathrm{O} K_{1}$ edges from XAS measurements, and (c) optical absorption constant from VUV SE.
TABLE I. Experimentally determined $\Delta\left(d^{*}\right)$ and $\Delta\left(d^{*}, s^{*}\right)$ energy splittings for $\mathrm{ZrO}_{2}$ and $\mathrm{HfO}_{2}$.

\begin{tabular}{lcccccc}
\hline \hline & \multicolumn{3}{c}{ Energy $( \pm 0.2 \mathrm{eV})$} & & \multicolumn{2}{c}{ Energy $( \pm 0.3 \mathrm{eV})$} \\
\cline { 2 - 3 } \cline { 7 - 7 } Spectrum & $d_{1}^{*}$ & $d_{2}^{*}$ & $s^{*}$ & & $\Delta\left(d^{*}\right)$ & $\Delta\left(d^{*}, s^{*}\right)$ \\
\hline $\mathrm{ZrO}_{2}-\mathrm{Zr} M_{2}$ & 345.9 & 347.7 & 357.5 & & 2.2 & 11.7 \\
$\mathrm{ZrO}_{2}-\mathrm{Zr} M_{3}$ & 332.6 & 334.8 & 344.5 & & 2.2 & 11.9 \\
$\mathrm{ZrO}_{2}-\mathrm{O} K_{1}$ & 532.2 & 535.4 & 542.3 & & 3.2 & 10.1 \\
$\mathrm{HfO}_{2}-\mathrm{Hf} N_{3}{ }^{\mathrm{a}}$ & $382.7^{\mathrm{a}}$ & $382.7^{\mathrm{a}}$ & 392.7 & & $<3.5^{\mathrm{b}}$ & $10^{\mathrm{a}}$ \\
$\mathrm{HfO}_{2}-\mathrm{O} K_{1}$ & 532.5 & 536.8 & 541.5 & & 4.3 & 9.0 \\
\hline \hline
\end{tabular}

${ }^{a}$ Doublet is not spectroscopically resolved.

${ }^{\mathrm{b}}$ Estimated from linewidth.

from experiment. The agreement between calculations and experiment is in the range of $\pm 0.3 \mathrm{eV}$.

Figure 3(a) compares $\mathrm{O} K_{1}$ NEXAFS data for a $\mathrm{Zr}$ silicate alloy $(x \sim 0.6)$ after a $900{ }^{\circ} \mathrm{C}$ anneal in (i), and as deposited in (ii). The spectrum in (i) is well approximated by a linear combination of the crystalline $\mathrm{ZrO}_{2} \mathrm{O} K_{1}$ spectrum of Fig. 2(b), and the $\mathrm{SiO}_{2} \mathrm{O} K_{1}$ spectrum. In the noncrystalline asdeposited film (ii), the higher energy component of the $\mathrm{Zr} d^{*}$ doublet overlaps the $\mathrm{Si} 3 s^{*}$ band and is not spectroscopically resolved. The $\mathrm{Si} 3 s^{*}$ and $\mathrm{Zr} 5 s^{*}$ states overlap with no resolvable features that can be assigned to either atomic state. The $\mathrm{Zr} 4 d^{*}$ state remains the lowest-lying conduction band state, and hence defines the onset of band gap transitions as in $\mathrm{ZrO}_{2}$. Studies of $\mathrm{Zr}$ silicate alloys with $0.35<x<0.70$ establish that the separation between the $\mathrm{Zr} 4 d^{*}$ and $\mathrm{Si} 3 s^{*}$ features is constant, but their relative intensities scale with alloy composition. A similar behavior occurs for Hf silicate alloys. This is shown in Fig. 3(b) for noncrystalline Hf silicate alloys, where the $\mathrm{Hf} 5 d^{*}$ state replaces the $\mathrm{Zr} 4 d^{*}$ state as the lowest energy transition. Our most important observation is that the conduction band edge, and therefore the conduction band offset energy with respect to $\mathrm{Si}$ in $\mathrm{Zr}$ and $\mathrm{Hf}$ silicate alloys is associated with the respective transition metal $d^{*}$ states and does not change in energy with silicate bonding. It is effectively pinned at the transition metal oxide value. A similar conclusion applies to $\mathrm{Zr}$ and $\mathrm{Hf}$ aluminate alloys, where the decrease in the band gaps between noncrystalline $\mathrm{Al}_{2} \mathrm{O}_{3}$ and $\mathrm{SiO}_{2}$, results in increased overlap between the $\mathrm{Al} 3 s^{*}$ state and respective transition metal $d^{*}$ states.

Having analyzed the transition metal silicate (and aluminate) conduction band edge, we now address the valence

TABLE II. Spin-orbit splittings of $p$-state.

\begin{tabular}{lccc}
\hline \hline & \multicolumn{3}{c}{$p$-state spin-orbit splitting $( \pm 0.5 \mathrm{eV})$} \\
\cline { 2 - 4 } Oxide & $\mathrm{TiO}_{2} 2 p$ & $\mathrm{ZrO}_{2} 3 p$ & $\mathrm{HfO}_{2} 4 p$ \\
\hline XAS spectra & 5.6 & 13.3 & 57.0 \\
Data Handbook $^{\mathrm{a}}$ & 6.4 & 13.7 & 57.5 \\
\hline \hline
\end{tabular}

${ }^{a} X$-ray Data Handbook, Lawrence Berkeley National Laboratory. 

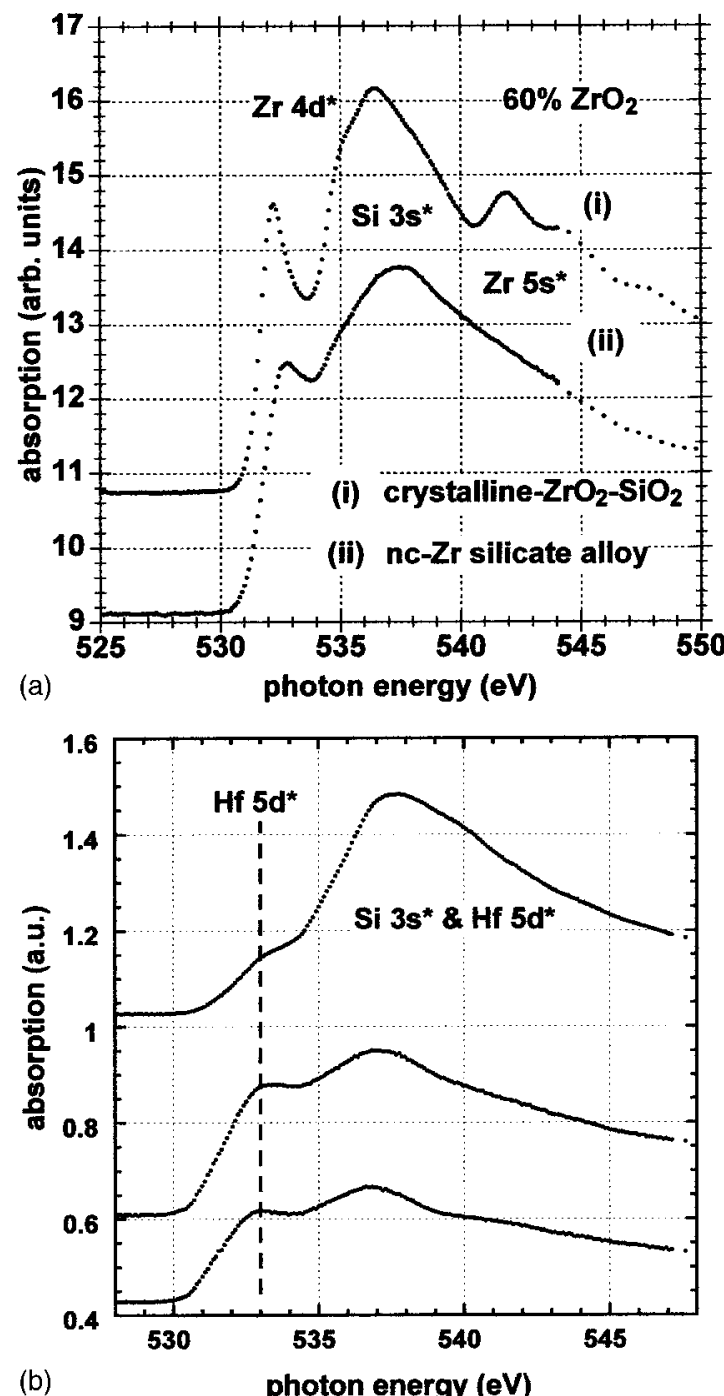

FIG. 3. Comparison of XAS O $K_{1}$ edges for (a) $\mathrm{Zr}$ and (b) Hf silicates. (a) Compares crystalline and phase-separated $\mathrm{Zr}$ silicate with $x \sim 0.6$, and (b) compares $\mathrm{Hf}$ silicate alloys with the $\mathrm{SiO}_{2}$ concentration increasing from $\sim 0.25$ to 0.75 (bottom to top).

band edge. For the AES $\mathrm{O}_{K L L}$ process in $\mathrm{SiO}_{2}$ it has been demonstrated that $L$ refers to nonbonding $\mathrm{O} 2 p \pi$ states at the top of the valence band. ${ }^{10}$ Thus

$$
\begin{aligned}
& E_{K}\left(\mathrm{O}_{K L L}\right)=E_{B}(\mathrm{O} 1 s)-2 E_{B}(\mathrm{O} 2 p)-\Omega, \\
& E_{B}(\mathrm{O} 2 p)=1 / 2\left[E_{B}(\mathrm{O} 1 s)-E_{K}\left(\mathrm{O}_{K L L}\right)-\Omega\right],
\end{aligned}
$$

where $E_{K}$ is the electron kinetic energy from AES, $E_{B}$ is an electron binding energy from XPS, and $\Omega$ includes all final state and Coulomb effects. Under the hypothesis that the same applies to the high $k$ materials under consideration, Eq. (1) can be used to estimate $E_{B}(\mathrm{O} 2 p)$ within $\Omega$ using $\mathrm{O}_{K L L}$ AES and O $1 s$ XPS data. This sets the stage for establishing $E_{B}(\mathrm{O} 2 p)$, the valence band edge energy, as a function of high $k$ alloy composition.

Figure 4(a) displays $\mathrm{O}_{K L L}$ AES and O 1s XPS data for $\mathrm{Zr}$ silicates in the whole range of possible compositions $(0<x$ $<1)$. XPS and UPS measurements have established that the valence band offset energies with respect to $\operatorname{Si} \Delta E_{V}$ are 4.6

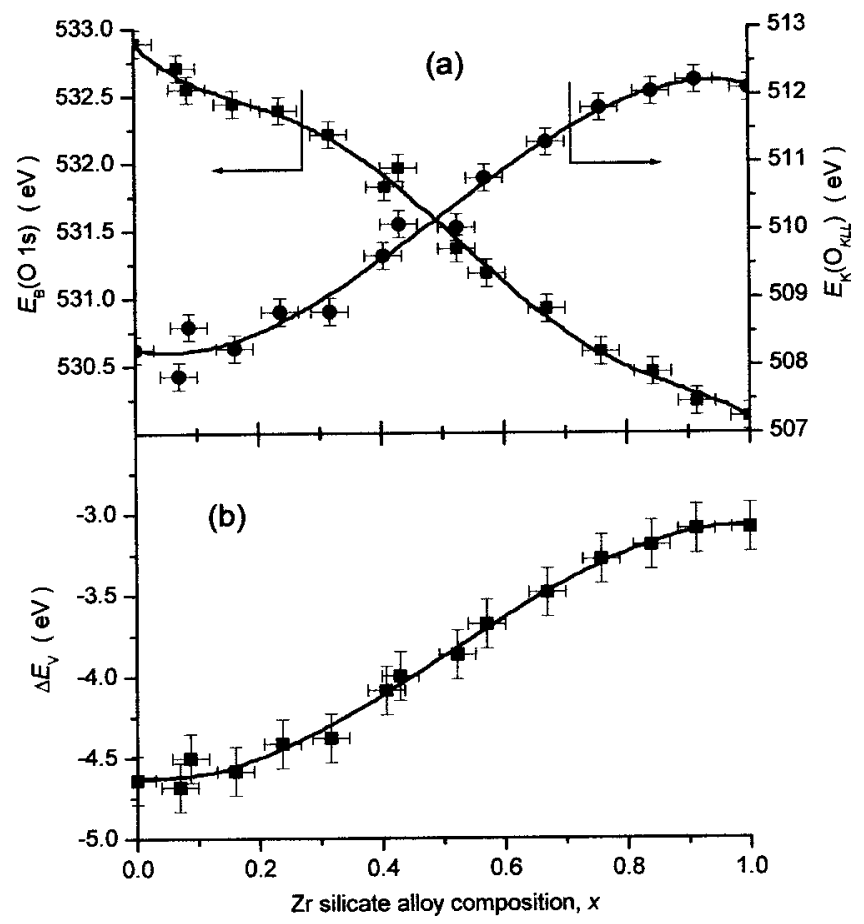

FIG. 4. (a) XPS O $1 s$ binding energy and AES $\mathrm{O}_{K L L}$ kinetic energy as a function of $\mathrm{Zr}$ silicate alloy composition. (b) Valence band offset with respect to $\operatorname{Si} \Delta E_{V}$ as given by Eq. (2).

$\mathrm{eV}$ for $\mathrm{SiO}_{2}(x=0)$ and $3.1 \mathrm{eV}$ for $\mathrm{ZrO}_{2}(x=1) .^{11,12}$ Starting from these values we apply a scaling with silicate composition that follows Eq. (1) to arrive at

$$
\Delta E_{V}(x) \approx-A \cdot 1 / 2 \cdot\left[E_{B}(\mathrm{O} \quad 1 s)-E_{K}\left(\mathrm{O}_{K L L}\right)\right]+B,
$$

with $A=0.44$ and $B=1.2$. Figure 4(b) displays the data corresponding to Eq. (2). The nonlinear change in valence band edge with silicate composition corresponds to changes in the average $\mathrm{O}$-atom bonding coordination, which increases from 2 in $\mathrm{SiO}_{2}$ to 3 in $\left(\mathrm{ZrO}_{2}\right)_{0.5}\left(\mathrm{SiO}_{2}\right)_{0.5}$, and to 4 in $\mathrm{ZrO}_{2}$. Figure 5 is the result of merging our findings regarding

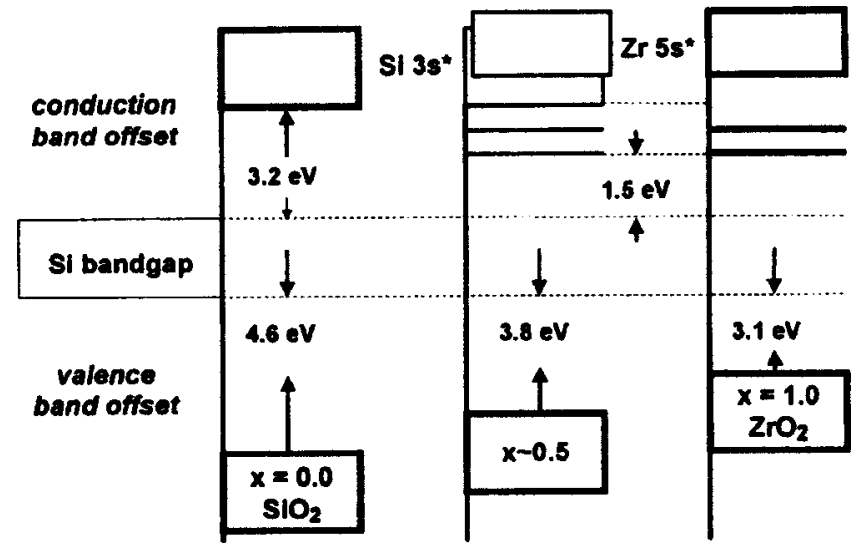

FIG. 5. Compositional dependence of band offset energies for $\mathrm{Zr}$ silicate alloys with respect to $\mathrm{Si}$. 


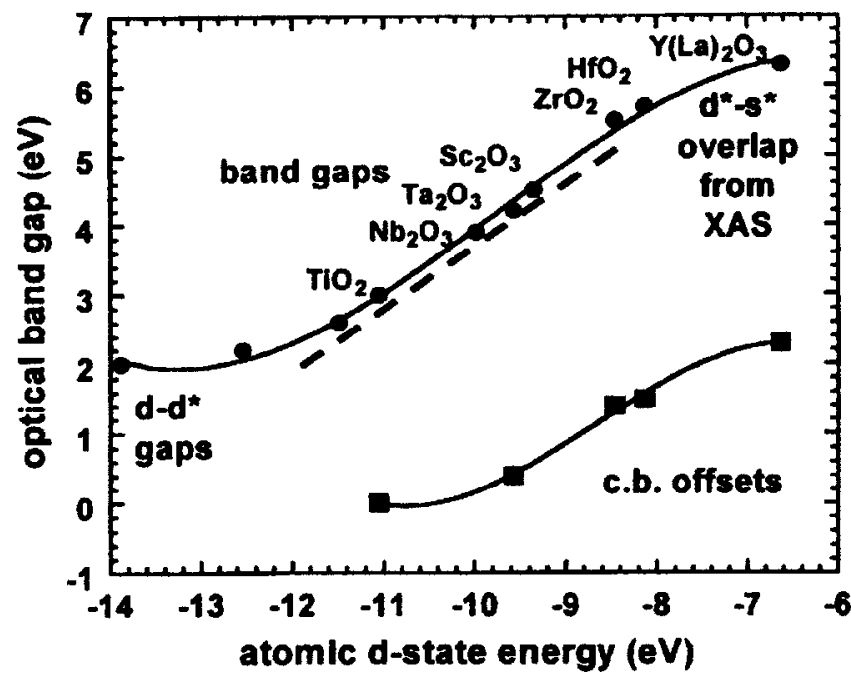

FIG. 6. Scaling of band gap and conduction band offset with respect to $\mathrm{Si}$ with transition metal and rare earth atomic $d$-state energy.

high $k$ conduction and valence band edges and alignment to Si. With $x$ increasing from $0\left(\mathrm{SiO}_{2}\right)$ to $1\left(\mathrm{ZrO}_{2}\right)$, one observes that:

- the conduction band offset is reduced. It is the same for the silicates and $\mathrm{ZrO}_{2}$ and does not change with silicate composition;

- the valence band offset is reduced. It is higher for the silicates as compared to $\mathrm{ZrO}_{2}$;

- the band gap of the dielectric decreases. The silicates show a wider band gap than $\mathrm{ZrO}_{2}$ due to the changing valence band edge.

We have obtained similar results for Hf silicate alloys using VUV SE, XAS, and XPS. XPS data from Hf aluminates show the same trend. ${ }^{13}$ Suitable weighting of our spectroscopic data reproduces the experimental ${ }^{14}$ optical band gap of $\mathrm{Zr}$ and Hf silicates.

Before addressing direct tunneling in silicate alloy systems, we consider transition metal and rare earth atomic $d$-state energy as a general scaling variable for high $k$ band gap and conduction band offset energy. Figure 6 displays the results of an empirical model originally deduced from a combination of experiment and model predictions. ${ }^{9}$ The model demonstrates a monotonic correlation of (i) oxide optical band gaps and (ii) oxide conduction band offset energies with respect to $\mathrm{Si}$ to transition metal and rare earth atomic $d$-state energy in the $s^{2} d^{\gamma-2}$ configuration ( $\gamma=3$ for Sc, Y, and $\mathrm{La}, 4$ for $\mathrm{Ti}, \mathrm{Zr}$, and $\mathrm{Hf}$, and 5 for $\mathrm{V}, \mathrm{Nb}$, and $\mathrm{Ta}$ ). Based on the previously shown results and discussion, this model qualitatively applies to silicate and aluminate alloys as well. The linear behavior between $\mathrm{Ti}$ and $\mathrm{Hf}$ and the extension to small $d$-state energies by Y and La defines the oxides that have received the most interest as potential candidates for replacing $\mathrm{SiO}_{2}$ and $\mathrm{Si}$ oxynitrides in complementary metaloxide-semiconductor (CMOS) applications. V, Ti, Nb, Ta, and Sc-based materials have been eliminated due to low conduction band offset with respect to $\mathrm{Si}$-less than $\sim 1 \mathrm{eV}$, taken as a threshold for technological applications due to the need to suppress electron tunneling. Due to the relevance of this issue we have also investigated electron tunneling through high $k$ silicates as a function of alloy composition.

Equation (3) indicates the tunneling transmission $T$ through a rectangular potential barrier, taken as an approximation for the case of a metal-dielectric-Si capacitor at low bias voltage

$$
T \propto \exp \left\lfloor-2 a t\left(E_{b} m^{*}\right)^{0.5}\right\rfloor,
$$

where $a$ is a constant, $t$ is the barrier width (dielectric layer thickness), $E_{b}$ is the barrier height (conduction band offset) and $m^{*}$ is the tunneling electron mass. Taking $\mathrm{SiO}_{2}$ as a benchmark, $t$ can be rewritten as $t_{\mathrm{ox}} k / k_{\mathrm{ox}}$, where $t_{\mathrm{ox}}$ is the equivalent $\mathrm{SiO}_{2}$ thickness, ${ }^{15} k$ is the dielectric constant of the high- $k$ under consideration, and $k_{\mathrm{ox}}$ is the dielectric constant of $\mathrm{SiO}_{2}$. Based on this picture we define a tunneling figure of merit given by

$$
\Phi=k\left(E_{b} m^{*}\right)^{0.5} .
$$

Significant increases in $k$ to values of 15-25 in transition metal and rare earth oxides are generally accompanied by decreases in $E_{b}$ and $m *$. Using an experimental approach, ${ }^{16}$ our group has determined the product $E_{b} m^{*}$ for $\mathrm{HfO}_{2}$ as $0.23 \pm 0.01 \mathrm{eV} m_{0}$ (where $m_{0}$ is the free electron mass). Based on the spectroscopic studies of $\mathrm{Zr}$ oxide and alloys, $E_{b}=1.5 \mathrm{eV}$ has been inferred for Hf oxide and alloys. This corresponds to $m^{*}=0.15 \pm 0.02 m_{0}$, in good agreement with other analysis of tunneling through $\mathrm{HfO}_{2}$ films. ${ }^{17}$ This mass

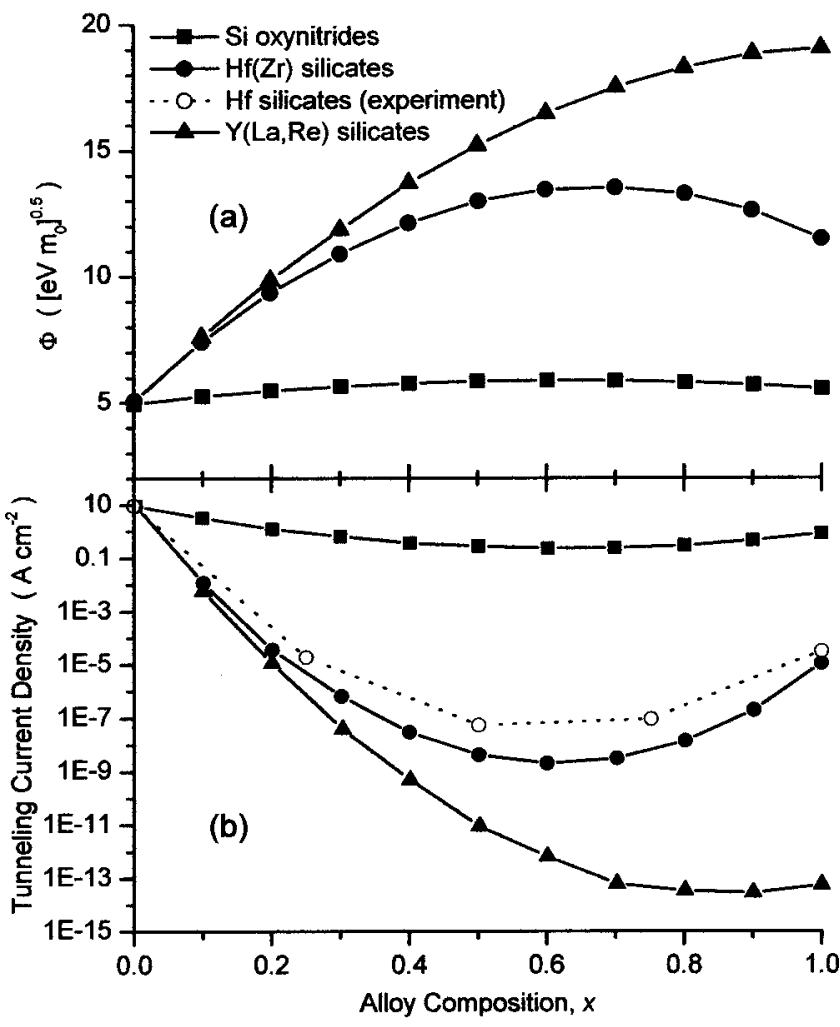

FIG. 7. (a) Compositional dependence of the tunneling figure of merit $\Phi$ for different high $k$ alloys. (b) Calculated tunneling current as a function of alloy composition ( $1 \mathrm{~V}$ bias, $1.2 \mathrm{~nm}$ equivalent $\mathrm{SiO}_{2}$ thickness). 

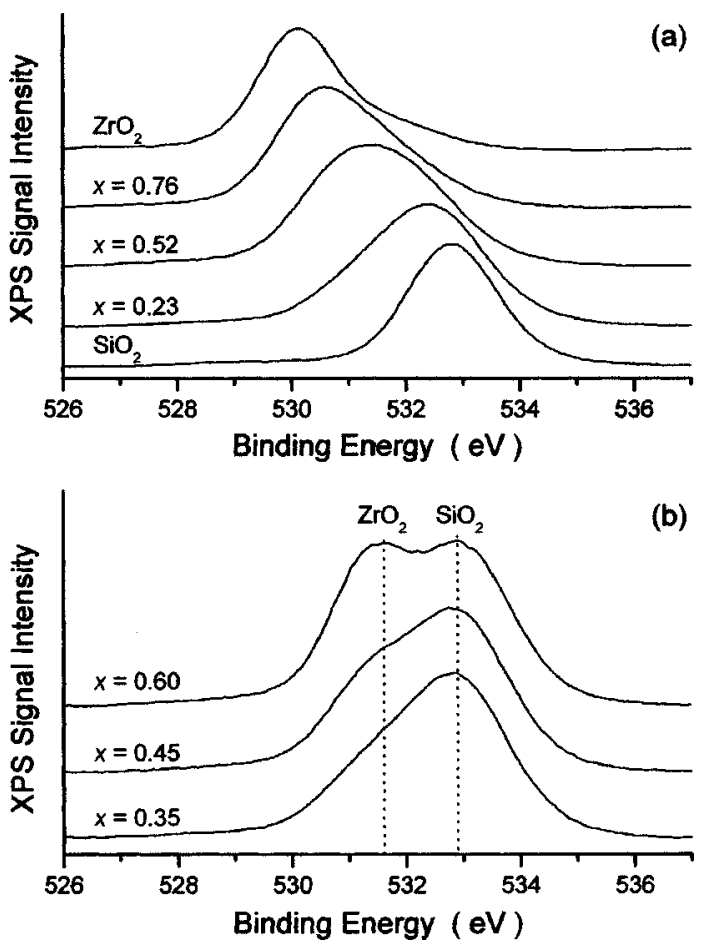

FIG. 8. XPS O $1 s$ spectra for $\mathrm{Zr}$ silicate films of various compositions: (a) as deposited and (b) after annealing at $900{ }^{\circ} \mathrm{C}$.

is significantly smaller than $m^{*} \sim 0.55 m_{0}$ for electrons in $\mathrm{SiO}_{2}$ and is consistent with the Franz two band model of Ref. 18.

In order to evaluate how $\Phi$ changes with composition for high $k$ alloys, one needs to know the dependence on composition of $k, E_{b}$, and $m^{*}$. We use averages of the values corresponding to the end-member oxides weighted by $x ; m^{*}$ in the high $k$ oxide is either estimated from the Franz two band model or experimentally determined. This procedure yields $\Phi(x)$ as displayed in Fig. 7(a). The monotonically increasing function for $\mathrm{Y}$ silicates predicts that tunneling with respect to $\mathrm{SiO}_{2}$ will be reduced over the entire alloy range, while the qualitatively different behavior predicts that the tunneling reduction in $\mathrm{Hf}$ silicate alloys will display a minimum at an intermediary composition. A WentzelKramers-Brillouin solution of the tunneling problem for 1.2 nm equivalent $\mathrm{SiO}_{2}$ thickness and a potential drop of $1 \mathrm{~V}$ across the dielectric yields the results displayed in Fig. 7(b). Experimental data are scaled to an equivalent $\mathrm{SiO}_{2}$ thickness of $1.2 \mathrm{~nm}$ assuming tenfold increase in tunneling current per $0.2 \mathrm{~nm}$ decrease in equivalent $\mathrm{SiO}_{2}$ thickness. ${ }^{19}$ The excellent agreement between simulated and experimental data supports our models. Based on our results, $x \sim 0.6$ provides the strongest suppression of electron tunneling in $\mathrm{Hf}$ silicates. In terms of $\mathrm{Si}$ technology, this also means that such silicate-not $\mathrm{HfO}_{2}$ - is the most scalable Hf-based replacement for $\mathrm{SiO}_{2}$. Although Hf oxide indeed has a higher $k$, that effect is mitigated by a decrease in $m^{*}$.

\section{CHEMICAL PHASE SEPARATION}

We now restrict ourselves to $\mathrm{Zr}$ silicates and compare spectroscopic data obtained as deposited and after annealing.

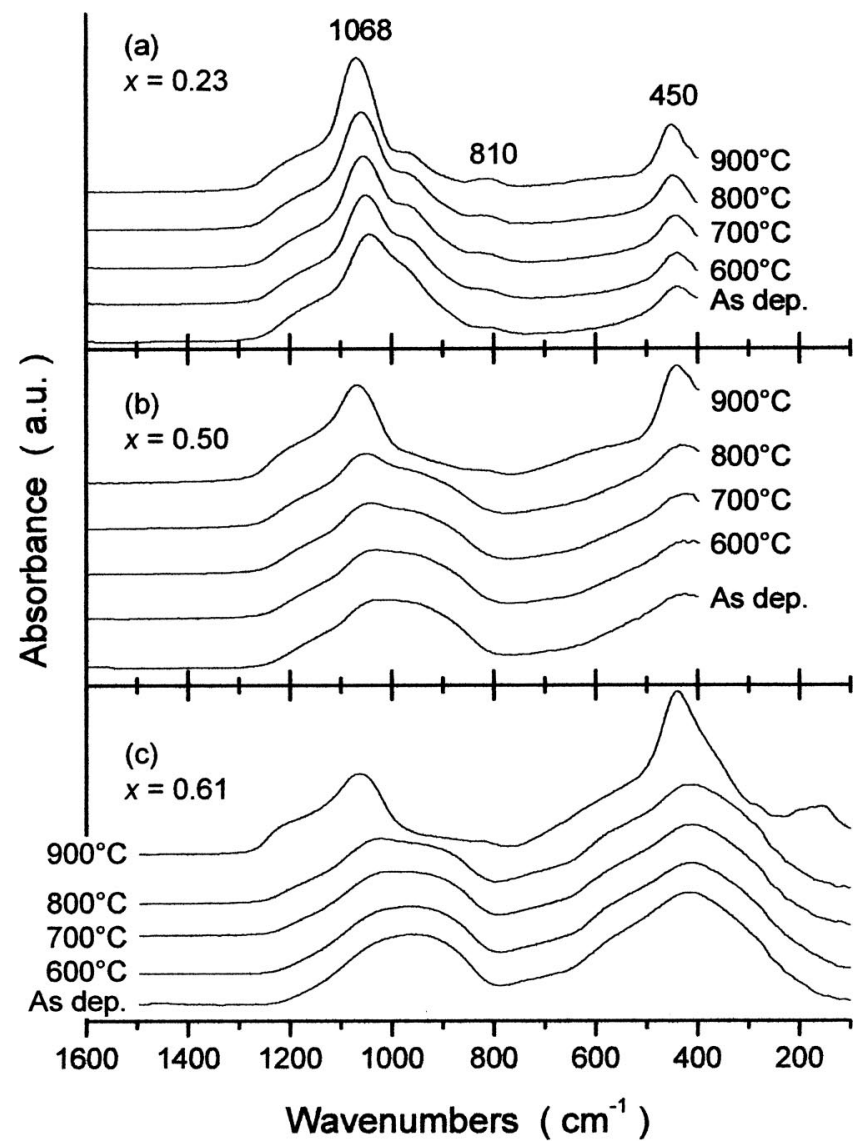

FIG. 9. FTIR spectra for $\mathrm{Zr}$ silicate films of various compositions [(a)-(c)], as deposited and after annealing at the temperatures indicated.

We show that there is thermally induced chemical phase separation above $800{ }^{\circ} \mathrm{C}$, and that the mode of separation depends on the metal content of the silicate. ${ }^{20}$

Figure 8 displays O $1 s$ XPS data. The systematic changes in line shape with alloy composition have been interpreted in terms of changes in the oxygen atom coordination, ${ }^{2}$ as noted above regarding the valence band edge. The spectra in Fig. 8(a) show asymmetric line shapes, whereas those in Fig. 8(b) clearly indicate two discrete and separated spectral components. The two features in these spectra are assigned to $\mathrm{SiO}_{2}$ and $\mathrm{ZrO}_{2}$-rich phases. This experimental result supports a recent analysis of the mixing thermodynamics of the $\mathrm{ZrO}_{2}-\mathrm{SiO}_{2}$ system in which the phase separation has been predicted as a result of spinodal decomposition. ${ }^{21}$

FTIR data are shown in Fig. 9. As a point of reference, the spectral range includes the $\mathrm{Si}-\mathrm{O}-\mathrm{Si}$ asymmetric stretching signal between 900 and $1300 \mathrm{~cm}^{-1}$, the $\mathrm{Si}-\mathrm{O}-\mathrm{Si}$ symmetric stretching (or bending) signal at about $810 \mathrm{~cm}^{-1}$, and the $\mathrm{Si}-\mathrm{O}-\mathrm{Si}$ out-of-plane rocking signal at about $450 \mathrm{~cm}^{-1}$, all for noncrystalline $\mathrm{SiO}_{2} \cdot{ }^{22,23}$ The spectral changes from Figs. 8(a) to 8(c) in the as-deposited sample are brought about by alloying with $\mathrm{ZrO}_{2}$. The shoulder at $970 \mathrm{~cm}^{-1}$ is not present in noncrystalline $\mathrm{SiO}_{2}$; it has been assigned ${ }^{24}$ to a stretching vibration of a terminal $\mathrm{Si}-\mathrm{O}$ bond formed by disruption of the $\mathrm{SiO}_{2}$ network upon formation of a pseudobinary alloy with $\mathrm{ZrO}_{2} \cdot{ }^{25,26}$ The spectrum for $x=0.50$ in Fig. 9(b) is for a 


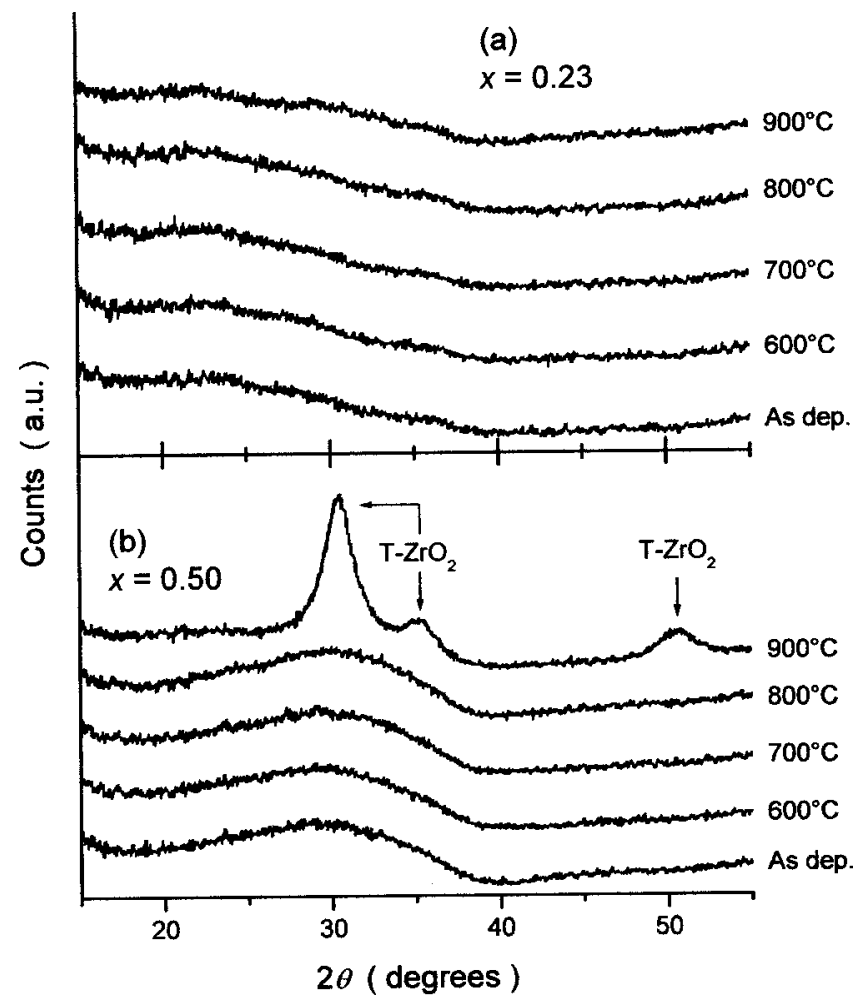

FIG. 10. XRD data for $\mathrm{Zr}$ silicate films of different composition [(a),(b)], as deposited and after annealing at the temperatures indicated.

chemically ordered alloy in which the $\mathrm{SiO}_{2}$ network has been completely disrupted. It is comprised of $\left(\mathrm{SiO}_{4}\right)^{4-}$ ions and $\mathrm{Zr}^{4+}$ ions, where the oxygen atoms have a threefold coordination. ${ }^{2}$ For the samples as-deposited and annealed below $900{ }^{\circ} \mathrm{C}$, the first broad feature centered at about 900 $\mathrm{cm}^{-1}$ is the signature of the $\left(\mathrm{SiO}_{4}\right)^{4-}$ ion. The second broad feature, centered at approximately $410 \mathrm{~cm}^{-1}$, is due to $\mathrm{Zr}-\mathrm{O}$ vibrations. This assignment is supported by the IR absorption spectrum of a crystalline $\mathrm{ZrO}_{2}$ sample (not shown). Spectra in Fig. 9 show essentially no change for annealing at up to $800{ }^{\circ} \mathrm{C}$, consistently with no detectable $\mathrm{OH}$ or $\mathrm{H}_{2} \mathrm{O}$ bands in the infrared spectrum (at high wave numbers, not shown). The changes observed after annealing at $900{ }^{\circ} \mathrm{C}$ are consistent with the chemical phase separation inferred from analysis of the O $1 s$ XPS data. In particular, a significant decrease of the feature at $970 \mathrm{~cm}^{-1}$ is consistent with a restriction of terminal $\mathrm{Si}-\mathrm{O}$ bonding to the boundaries of the $\mathrm{SiO}_{2}$ - and $\mathrm{ZrO}_{2}$-rich phases.

XPS and FTIR results are complemented by XRD data. The broad feature shown for an as-deposited sample with $x$ $=0.50$ in Fig. 10(b) does not change after annealing at up to $800^{\circ} \mathrm{C}$, but data obtained after annealing at $900^{\circ} \mathrm{C}$ clearly identify the tetragonal crystalline phase of $\mathrm{ZrO}_{2}$. In contrast, no indication of crystallinity appears in Fig. 10(a), which corresponds to a sample with $x=0.23$. This suggests that the details of phase separation depend on the original composition of the silicate. It is interesting to note that the thermodynamically favored phase of crystalline $\mathrm{ZrO}_{2}$ at room temperature and pressure is monoclinic. At room temperature,
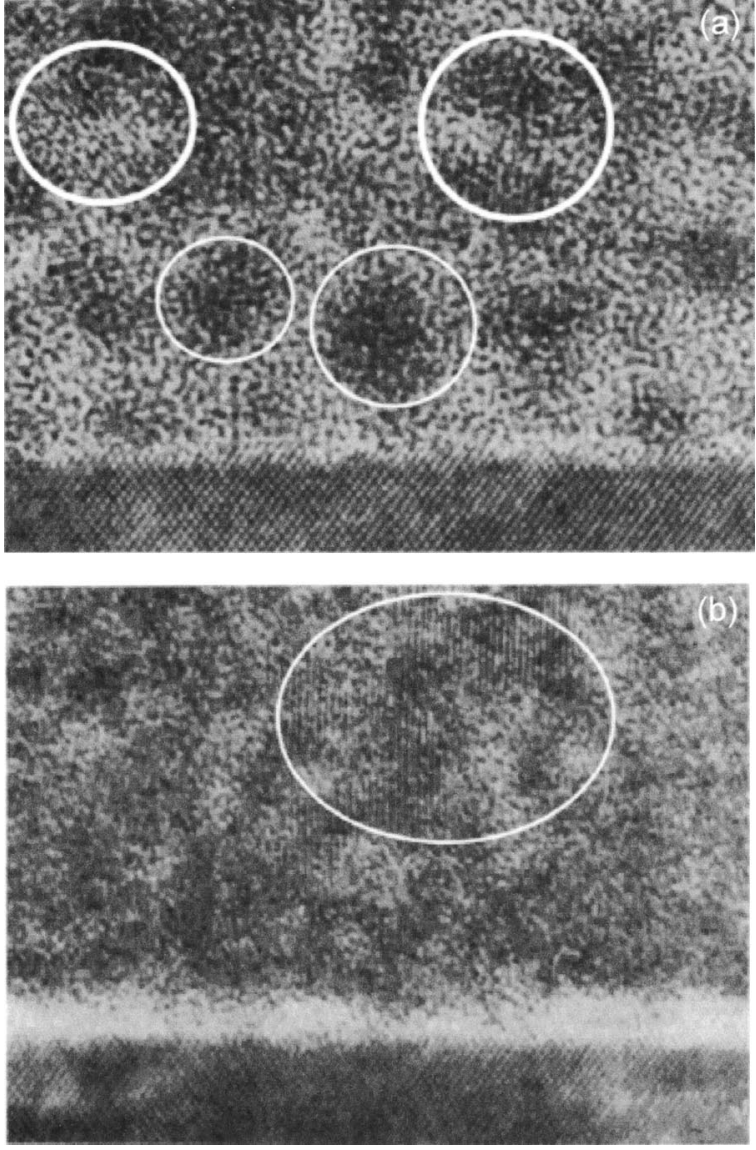

FIG. 11. HRTEM images for $\mathrm{Zr}$ silicate samples after annealing at $900{ }^{\circ} \mathrm{C}$ : (a) $x \sim 0.25$; (b) $x \sim 0.50$.

the tetragonal phase becomes favored at high pressures, which in our sample would be a result of the surrounding $\mathrm{SiO}_{2}$-rich phase.

Figure 11 displays HRTEM images obtained after annealing at $900{ }^{\circ} \mathrm{C}$. The darker regions are assigned to the $\mathrm{ZrO}_{2}$-rich phase. Figure 11(a) evidences $\mathrm{ZrO}_{2}$ crystallites in a sample with $x \sim 0.25$. Based on the spacing of lattice planes in the Si substrate, the crystallite size ranges from 3 to $5 \mathrm{~nm}$. As mentioned above, these nanocrystallites were not detected by XRD. For example, XRD can readily detect crystallites as small as $10 \mathrm{~nm}$; however, as the crystallite size decreases, the width of an XRD peak increases, and it is generally difficult to detect features as small as $3-5 \mathrm{~nm}$. Figure 11(b), which corresponds to a sample with $x \sim 0.50$, shows a microcrystallite that is about 2-3 times larger than the ones in Fig. 11(a). Thus, HRTEM identifies the original silicate composition as determining the size of the $\mathrm{ZrO}_{2}$ crystallites resulting from phase separation.

Figure 12 displays radial distribution functions (RDFs) obtained from the analysis ${ }^{27}$ of $\operatorname{Zr} M_{2,3}$ EXAFS data. Asdeposited samples with $x \sim 0.25$ and 0.55 yield essentially the same result, except for a narrowing of the $\mathrm{Zr}-\mathrm{O}$ peak and reduction of a satellite feature at about $3 \AA$ for low $x$. Annealing at $900{ }^{\circ} \mathrm{C}$ results in a distinguished feature slightly above $3 \AA$ and in weaker signals below 5 and $7 \AA$. The peak labeled $\mathrm{Zr}-\mathrm{Zr}$ corresponds to a second-nearest neighbor dis- 


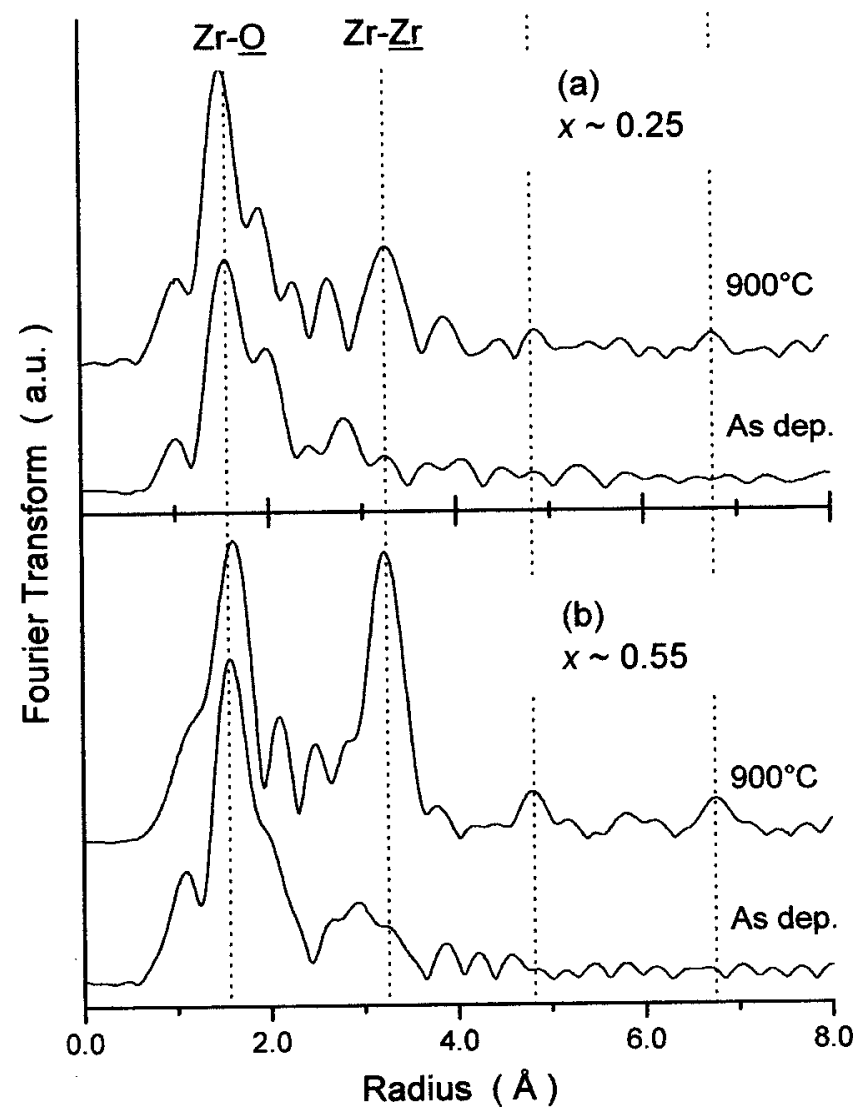

FIG. 12. Radial distribution functions from $\mathrm{Zr} M_{2,3}$ EXAFS data for $\mathrm{Zr}$ silicates of different composition [(a),(b)], as deposited and after annealing at $900{ }^{\circ} \mathrm{C}$.

tance, and the additional features, to more distant $\mathrm{Zr}-\mathrm{O}$ and $\mathrm{Zr}-\mathrm{Zr}$ coordination shells. The three signals resulting from annealing are stronger in the sample with $x \sim 0.55$. The emergence of second-nearest neighbor $\mathrm{Zr}-\mathrm{Zr}$ features is clear evidence of order on a crystalline scale. The differences between the RDFs after annealing are consistent with increased crystalline order (crystallite size) in the alloy with $x \sim 0.55$ as compared to that with $x \sim 0.25$, in agreement with HRTEM data.

\section{CONCLUSIONS}

We have presented a comprehensive spectroscopic characterization of $\mathrm{Zr}$ and $\mathrm{Hf}$ silicate alloys. Band alignment with respect to silicon has been shown as a function of alloy composition. The atomic $d$-state energy of transition metal and rare earth elements has been shown to be a valuable scaling variable for the electronic properties of high $k$ materials. Electron tunneling has been predicted as a function of high $k$ alloy composition in remarkable agreement with experimen- tal data, showing that $\left(\mathrm{HfO}_{2}\right)_{x}\left(\mathrm{SiO}_{2}\right)_{1-x}$ with $x \sim 0.6$ is the most scalable Hf-based high $k$ substitute to Si oxide (oxynitrides). Chemical phase separation was observed in the $\mathrm{Zr}$ silicate system after annealing at $900{ }^{\circ} \mathrm{C}$ and is a point of concern regarding technological applications.

\section{ACKNOWLEDGMENTS}

Supported in part by the ONR, AFSOR, SRC, and the SRC/International SEMATECH Front End Processes Center.

${ }^{1}$ G. Lucovsky, IBM J. Res. Dev. 43, 301 (1999).

${ }^{2}$ G. B. Rayner, Jr., D. Kang, Y. Zhang, and G. Lucovsky, J. Vac. Sci. Technol. B 20, 1748 (2002).

${ }^{3}$ J. L. Whitten, Y. Zhang, M. Menon, and G. Lucovsky, J. Vac. Sci. Technol. B 20, 1710 (2002).

${ }^{4}$ G. Lucovsky, J. L. Whitten, and Y. Zhang, Microelectron. Eng. 59, 329 (2001).

${ }^{5}$ G. Lucovsky, Microelectron. Reliab. 43, 1417 (2003).

${ }^{6}$ C. J. Ballhausen and H. B. Gray, Molecular Orbital Theory (Benjamin, New York, 1964), Chap. 8.

${ }^{7}$ P. A. Cox, Transition Metal Oxides (Oxford Science, Oxford, 1992), Chap. 2.

${ }^{8}$ G. Lucovsky, G. B. Rayner, Jr., D. Kang, G. Appel, R. S. Johnson, Y. Zhang, D. E. Sayers, H. Ade, and J. L. Whitten, Appl. Phys. Lett. 79, 1775 (2001).

${ }^{9}$ J. Robertson, J. Vac. Sci. Technol. B 18, 1785 (2000).

${ }^{10}$ D. E. Ramaker, J. S. Murday, and N. H. Turner, in The Physics of $\mathrm{SiO}_{2}$ and its Interfaces, edited by S. T. Pantelides (Pergamon, New York, 1978), p. 99.

${ }^{11}$ S. Miyazaki and M. Hirose, AIP Conf. Proc. 550, 89 (2000).

${ }^{12}$ S. Miyazaki, M. Narasaki, M. Ogasawaga, and M. Hirose, Microelectron. Eng. 59, 373 (2001).

${ }^{13}$ H. Y. Yu, M. F. Li, B. J. Cho, C. C. Yeo, M. S. Joo, D.-L. Kwong, J. S. Pan, C. H. Ang, J. Z. Zheng, and S. Ramanathan, Appl. Phys. Lett. 81, 376 (2002).

${ }^{14}$ H. Kato, T. Nango, T. Miyagawa, T. Katagiri, K. S. Seol, and Y. Ohki, J. Appl. Phys. 92, 1106 (2002).

${ }^{15}$ The equivalent oxide thickness $t_{\mathrm{ox}}$ is the thickness of $\mathrm{SiO}_{2}$ that, in an MOS capacitor, produces the same capacitance as a thickness $t$ of high $k$ material.

${ }^{16}$ C. L. Hinkle, C. Fulton, R. J. Nemanich, and G. Lucovsky, Microelectron. Eng. 72, 257 (2004).

${ }^{17}$ T. P. Ma (unpublished).

${ }^{18}$ J. Maserjian, J. Vac. Sci. Technol. 11, 996 (1974).

${ }^{19}$ M. L. Green, E. P. Gusev, R. Degraeve, and E. L. Garfunkel, J. Appl. Phys. 90, 2057 (2001).

${ }^{20}$ G. B. Rayner, Jr., D. Kang, and G. Lucovsky, J. Vac. Sci. Technol. B 21, 1783 (2003).

${ }^{21}$ H. Kim and P. C. McIntyre, J. Appl. Phys. 92, 5094 (2002).

${ }^{22}$ F. L. Galeener and G. Lucovsky, Phys. Rev. Lett. 37, 1474 (1976).

${ }^{23}$ G. Lucovsky, C. K. Wong, and W. B. Pollard, J. Non-Cryst. Solids 59, 60 , 839 (1983).

${ }^{24}$ G. B. Rayner, Jr., R. Therrien, and G. Lucovsky, Mater. Res. Soc. Symp. Proc. 611, c13.1 (2001).

${ }^{25}$ J. P. Maria, D. Wicaksana, A. I. Kingon, B. Busch, H. Schulte, E. Garfunkel, and T. Gustafsson, J. Appl. Phys. 90, 3476 (2001).

${ }^{26}$ G. D. Wilk, R. W. Wallace, and J. M. Anthony, J. Appl. Phys. 89, 5243 (2001).

${ }^{27}$ X-Ray Absorption: Principles, Applications, Techniques of EXAFS, SEX$A F S$ and XANES, edited by D. C. Koningsberger and R. Prins (Wiley, New York, 1988). 